\title{
Novel Integrated Ultrafiltration and Reverse Osmosis System in High Quality Drinking water Production
}

\author{
VINOD KUMAR S $^{2 *}$ and R BASKARAN ${ }^{1}$ \\ ${ }^{2}$ Research Scholar, Sathyabama Institute of science and Technology, Chennai,Tamilnadu, India, \\ 'Department of Chemical Engineering, St.Joseph's College of Engineering, Chennai, Tamilnadu, India. \\ *Corresponding author E-mail: vinodking20@gmail.com \\ http://dx.doi.org/10.13005/ojc/360634 \\ (Received: November 16, 2020; Accepted: December 17, 2020)

\begin{abstract}
Modernization in water technology plays a major role in ensuring a clean, safe, and feasible supply of drinking water. Enhancing performance in terms of price and quality, flow ability of the plant, sustainable development; integrated membrane processes have been developed. The most crucial issues found in RO applications such as concentration polarization and membranes fouling are reduced by using this integration of membranes. Conventional reverse osmosis filtration has sand and coke filters as pre filters. In this work these pre filters have been replaced by ultra-filtration which ensures undoubtedly the best quality of water despite the quality of feed with low power consumption and chemicals. These integrated systems are the better thing for complete elimination of microorganism and water contaminants in their category of selection. The present work also contributes on water quality analysis for brackish water using both the above desalination membrane technology. This integrated
\end{abstract} \\ system can be remotely monitored and self-adapted model-based control.
}

Keywords: Reverse osmosis, Ultra filtration, Desalination membrane technology, Membrane fouling, Integrated system, Pre filters.

\section{INTRODUCTION}

The scarcity of potable water poses a big problem where freshwater is becoming very scarce and expensive. ${ }^{1}$ One of the major international health issues in today's scenario is clean drinking water. Nearly 25 percent of global world has no access for fresh water ${ }^{2}$. All the parts of world found to have abundant fresh water and the main issue is all these waters are polluted either directly or indirectly by natural sources or manmade activity. Revolution in modernization and development in industries and their machinery operation need clean water for their process. Thus the demand for the clean water is magnificently expanded more and made the current scenario scarce. As a result, water consumption -related deaths in the earth are currently a major possible cause of mortality. It is more alarming issue in this existing situation consuming polluted water and death rate due to water contamination ${ }^{3}$.

One of the development in which required membrane purifying water that uses the reverse osmosis membrane is progressively transferred via the solvent (typically water) is reverse osmosis ${ }^{4}$. Pressure act as a hub for resolving water hydrostatic

This is an Open Access article licensed under a Creative Commons license: Attribution 4.0 International (CC- BY). Published by Oriental Scientific Publishing Company @ 2018 
gradient. Integrated membrane module may be severely affected by RO Membrane pore size, concentration factors, membrane roughness, chemical stability and other factors, such as fouling, scaling and premature membrane deteriorartion. This can result in reduced of flux, lesser rejection rate higher pressure drops, shorter membrane life and high operating costs. Ultrafiltration (UF) is tested to be competitive compared to standard treatments. UF is used to supplement the approval process, i.e; co-precipitation, sedimentation and filtration, in standard desalination plants and can be described as the clarification and disinfection of the membrane activity. UF membranes are normally permeable and all impurities microbes, particularly macromolecules, such as microorganisms are refused. Compared to other traditional clarification and disinfection (post chlorination) methods, the primary characteristics of low pressure UF membrane processes are the necessity of negligible chemicals, girth filtration as opposed to media depth filtration, strong and constant consistency of treated water in terms of particle and microorganism reduction regardless of water quality process and plate filtration. Source quality of water greatly impacts UF membrane performance. In an external flow configuration with a relatively modest pore diameter, ultra filtration PVDF flat sheet membrane make it a great choice to safeguard all downstream such as reverse osmosis. With an industry leading ultra filtration membrane region of low energy and chemical utilization, the modules retain the optimum showing, accurately reducing the amount of configuration for the design. The pore size range between 0.01 to $0.1 \mu \mathrm{m}$, the pore sizes of ultra filtration membrane pore size fall between that of nanofiltration and microfiltration. The main advantage of UF is that specified given transmembrane pressure, the membrane flux is much greater for UF than $\mathrm{RO}$. The energy required is less for specified flow rate of UF membrane than to RO membrane of same surface area. For low pressure application, UF has made us apractical alternative. The success of membrane lies in the following pretreatment processes(1) Application areas influence desalination of seawater, treatment of wastewater, separation in the biotechnology and food industries and chemical production.

\section{MATERIALS AND METHODS}

Collection of Samples: The water sample from different parts of Chennai were collected and classified based on TDS of water sample.

\section{Physico-chemical Analysis}

The collected water samples were tested by using physical and chemical analysis method. The physical analysis includes the determination of Total suspended solids, Total dissolved solids, $\mathrm{PH}$, conductivity, salinity, turbidity and the chemical analysis are shown below:

\section{Estimation of Suspended Solids (Non-Filterable Solids)}

The Cauldron is washed with a filter paper that is ignited in the oven at a watch glass (W1).Then the sample weighs $25 \mathrm{~mL}$ and via the cauldron, filtered. The dried crucible is kept at $103^{\circ} \mathrm{C}$ for $24 \mathrm{~h}$, allowed to cool in the desiccators and weighed (W2). The value of the suspended solids is calculated as follows:

$$
T S S=\frac{W 2-W 1}{V} \times 100 \mathrm{mg} / \mathrm{ml}
$$

Where : W1 $=$ Weight of empty cauldron along with filter paper in $\mathrm{mg}$

W2 = Weight of the cauldron in addition with filter paper after drying in $\mathrm{mg}$

$\mathrm{V}=$ Volume of the sample taken in $\mathrm{mL}$.

\section{Estimation of Total dissolved solids}

Total dissolved solid was evaluated by simple method based on evaporating the water samples to dryness. The $50 \mathrm{~mL}$ of given sample were taken in evaporating dish by heating for drying at $180^{\circ} \mathrm{C}$ to a constant mass for 1 to 2 hours. Total dissolved solids were calculated as follows:

$$
T D S=\frac{m g \text { of residue }}{\text { ml of sample }} \times 1000
$$

\section{Estimation of $\mathrm{pH}$ of the water sample}

The $\mathrm{pH}$ of the sample is measured by the theory of ionization of water due to formation of hydrogen ion $\left(\mathrm{H}^{+}\right)$and hydroxyl ion $\left(\mathrm{OH}^{-}\right)$. The $\mathrm{pH}$ scale is used to calculate the $\mathrm{pH}$ of the medium, i.e. the acidity or alkalinity of the medium. The $\mathrm{pH}$ meter is set to level surface. The electrode calibration was done using the suitable buffer solution. After calibration, the $\mathrm{pH}$ meter, the electrode is washed by dipping 
into deionised water to remove any adhering buffer. The sample solution is collected and the electrode is immersed in it and its reading is noted. Once again $\mathrm{pH}$ of the sample is measured by washing the electrode by dipping it in distilled water.

\section{EXPERIMENTAL}

The sample water treatment process in this system includes following phases. During the first phase, the sample ground water passes through a sediment filter. All of the pollutants and retained solid are removed in this first stage. Then water sample send to UF membrane chamber where the removal of macromolecules of the given treated water sample. Then this sample is sent to main chamber where the water is passed through a semi permeable filter at pressure of $30-40$ psi thus the RO purification process is done. The suspended impurities including lead, pesticides, sulphates and nitrates, passes with a very narrow pore diameter of 0.01 micron. The final chamber process uses UV lamp pf 11 watts to put the water UV filtration. The water is made of free of germs and safe for drinking by removing all microorganism. The advantage of ultraviolet rays, extremely deadly to microorganism, is that attack them completely so that they cannot replicate. This process is more unique that without addition of any chemicals, $99.9 \%$ of all microorganisms are killed. Finally the treated water is collected in pure water tank.

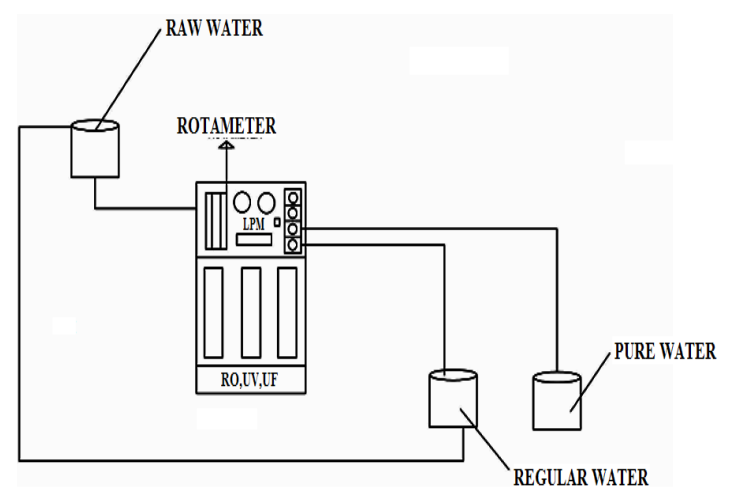

Fig. 1. Experimental set up (RO-UF set up) RESULTS

The collected water samples were tested by using physical and chemical analysis method. The physical analysis includes the determination of Total suspended Solids, Total dissolved solids, $\mathrm{pH}$, conductivity, salinity, turbidity and odour are shown in Table 1.The collected water samples were tested by using chemical analysis method. The chemical analysis values for raw water samples are shown in Table 2.

Table 1: Physical Analysis of water

\begin{tabular}{cccc}
\hline Parameter & \multicolumn{3}{c}{$\begin{array}{c}\text { Raw water samples } \\
\text { at room temperature }\end{array}$} \\
& \multicolumn{3}{c}{3} \\
Samples & 1 & 2 & 3 \\
Total dissolved solids ppm & 500 & 1000 & 1500 \\
Total suspended solids & 3 & 4 & 8 \\
$\mathrm{pH}$ value at $25^{\circ} \mathrm{C}$ & 6.81 & 6.71 & 7.23 \\
Conductivity & 1250 & 1460 & 1700 \\
Salinity ppm & 450 & 730 & 810 \\
Odour & $\mathrm{NIL}$ & $\mathrm{NIL}$ & $\mathrm{NIL}$ \\
Turbidity (NTU)A & 1 & 1 & 1 \\
\hline
\end{tabular}

Table 2: Chemical Analysis of water

\begin{tabular}{cccc}
\hline Parameter & \multicolumn{3}{c}{$\begin{array}{c}\text { Raw Water Samples } \\
\text { at Room Temperature }\end{array}$} \\
\hline Samples & 1 & 2 & 3 \\
Total Hardness as $\mathrm{CaCo}_{3}$ & 320 & 421 & 541 \\
Calcium Hardness as $\mathrm{CaCO}_{3}$ & 251 & 327 & 421 \\
Chlorides as Cl & 250 & 451 & 1100 \\
Sulfates as $\mathrm{SO}_{4}$ & 280 & 320 & 540 \\
Total Iron as Fe & 0.31 & 0.42 & 0.48 \\
Calcium as Ca & 104 & 202 & 284 \\
Magnesium as Mg & 21 & 45 & 49 \\
Manganese (mg/L) & 0.1 & 0.12 & 0.15 \\
Zinc & 1.0 & 1.0 & 1.0 \\
COD & 3 & 2.4 & 2.1 \\
\hline
\end{tabular}

\section{DISCUSSIONS}

The ultra filtration process is the solution separation process in which there is the variation in pressure between two sides of the membrane as the guiding factor, and the mechanical separation ${ }^{5}$. The pore size of sieve is $0.01-0.1 \mu \mathrm{m} .{ }^{6}$ UF may remove particles such as colloidal particle, bacteria, virus, macromolecule organics, etc., but it may not reduce low molecular organics or ionic pollutants ${ }^{7}$. Based on total dissolved solids of samples, other physical parameters are varying. Permeate volume and permeate flux has been given in Table 4. Individual treatment with UF membrane and integration membrane has been given separately in Table 5 .

Table 3: Specifications of Integrated portable UF and RO system

\begin{tabular}{ccc}
\hline Specifications & Ultra filtration & Reverse osmosis \\
\hline Material & Hollow fiber & PTFE \\
Flow & 500 litres $/ \mathrm{hr}$ & 500 litres $/ \mathrm{h}$ \\
Automation & automatic & Automatic \\
Pore size & 0.1 microns & 0.0001 microns \\
\hline
\end{tabular}


Table 4: Permeate Volume \& Permeate Flux

\begin{tabular}{|c|c|c|c|c|c|c|}
\hline \multirow[t]{2}{*}{ Time (min) } & \multicolumn{3}{|c|}{$\begin{array}{c}\text { Permeate Volume } \\
(\mathrm{mL})\end{array}$} & \multicolumn{3}{|c|}{$\begin{array}{l}\text { Permeate Flux } \times 10^{-3} \\
\qquad 1 / \mathrm{m}^{2} \mathrm{~h}\end{array}$} \\
\hline & 1 & 2 & 3 & 1 & 2 & 3 \\
\hline \multirow[t]{2}{*}{1} & & & & & & 0.84 \\
\hline & 65 & 80 & 82 & 0.8 & 0.82 & \\
\hline \multirow[t]{2}{*}{2} & & & & & & 0.79 \\
\hline & 140 & 142 & 148 & 0.76 & 0.77 & \\
\hline \multirow[t]{2}{*}{3} & & & & & & 0.76 \\
\hline & 200 & 210 & 215 & 0.74 & 0.75 & \\
\hline \multirow[t]{2}{*}{4} & & & & & & 0.75 \\
\hline & 240 & 268 & 280 & 0.72 & 0.73 & \\
\hline \multirow[t]{2}{*}{5} & & & & & & 0.73 \\
\hline & 343 & 358 & 395 & 0.72 & 0.72 & \\
\hline \multirow[t]{2}{*}{6} & & & & & & 0.73 \\
\hline & 425 & 480 & 490 & 0.72 & 0.72 & \\
\hline \multirow[t]{2}{*}{7} & & & & & & 0.74 \\
\hline & 485 & 490 & 495 & 0.72 & 0.73 & \\
\hline \multirow[t]{2}{*}{8} & & & & & & 0.74 \\
\hline & 520 & 540 & 555 & 0.71 & 0.72 & \\
\hline \multirow[t]{2}{*}{9} & & & & & & 0.72 \\
\hline & 624 & 680 & 710 & 0.71 & 0.71 & \\
\hline
\end{tabular}

The parameter like $\mathrm{pH}$, conductivity, salinity increases with increase in Total dissolved solids from data observation higher the Total dissolved solids of water, higher the electrical conductivity of water sample ${ }^{8}$.The carbonate, bicarbonate and $\mathrm{CO}_{2}$ concentration as a part of Total dissolved solids can affect on the values of $\mathrm{pH}$. The total dissolved solids concentration is the total charged ions present in the water sample (sum of cations and anions) ${ }^{9}$. The conductivity increases as salinity increases because of the conduction of electric current due to dissolved salts and other inorganic chemicals. Permeate volume increases with increase in time shown in Fig. 2. Permeate flux decreases slowly with time shown in Fig. 3, with the increase in the concentration. In constant concentration case complete reuse of permeate and retentate is maintained. The ultra filtration membrane has remarkable role on removal of iron. The water present in the iron is in the form of flocs or complexes and few of iron are in Free State. Small molecule organic contaminants are not removed by ultra filtration ${ }^{10}$, experiments show that ultra filtration does not have separation effect on COD and Mn.

Table 5: After Treatment with Ultra filtration and Reverse osmosis

\begin{tabular}{|c|c|c|c|c|c|c|}
\hline & \multicolumn{3}{|c|}{ After UF treatment after } & \multicolumn{3}{|c|}{$\begin{array}{c}\text { Treatment with integrated } \\
\text { UF, RO, UV }\end{array}$} \\
\hline Samples & 1 & 2 & 3 & 1 & 2 & 3 \\
\hline Total Hardness as $\mathrm{CaCo}_{3}$ & 320 & 421 & 541 & 9.0 & 9.5 & 9.8 \\
\hline Turbidity & 0.5 & 0.5 & 0.5 & 2 & 3 & 4 \\
\hline Total hardness & 250 & 300 & 320 & 122 & 124 & 136 \\
\hline Sulfates as $\mathrm{SO}_{4}$ & 180 & 220 & 240 & 10 & 12 & 13 \\
\hline Total Iron as Fe & 0.10 & 0.11 & 0.13 & 0.1 & 0.1 & 0.1 \\
\hline Calcium as $\mathrm{Ca}$ & 100 & 102 & 184 & 52 & 56 & 58 \\
\hline Magnesium as Mg & 21 & 45 & 49 & 10 & 12 & 14 \\
\hline Manganese (mg/L) & 0.09 & 0.1 & 0.15 & 0.01 & 0.02 & 003 \\
\hline Zinc & 0.9 & 1.0 & 1.0 & 1 & 1 & 1 \\
\hline COD & 2.8 & 2.4 & 2.1 & 1 & 1 & 1 \\
\hline TDS & 400 & 890 & 1260 & 82 & 88 & 92 \\
\hline
\end{tabular}

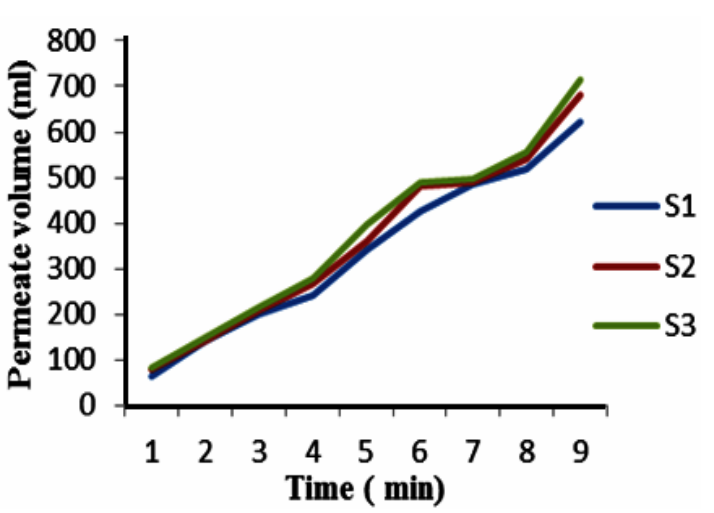

Fig. 2. Permeate volume vs Time of different samples water

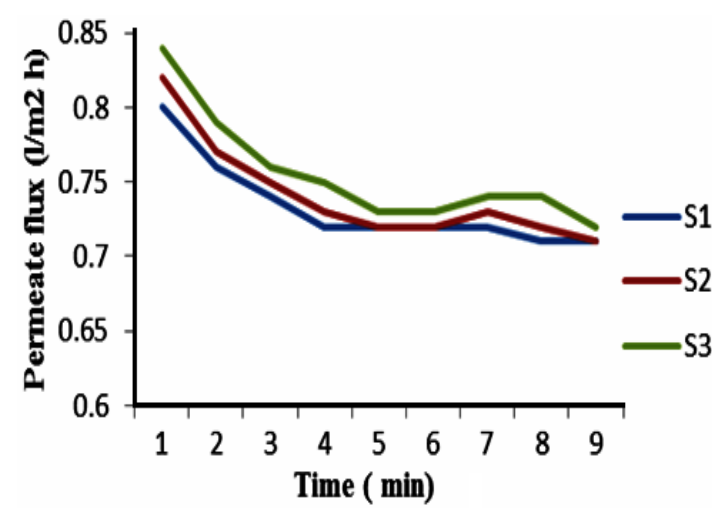

Fig. 3. Permeate flux vs Time of different sample water 


\section{CONCLUSION}

This integrated system is a great choice for virus, pathogens, dissolved particles, colloidal particles and water contaminants to be highly removable. Ultrafiltartion (UF) has been shown to be efficient in treatment compared with traditional treatment. UF is used to remove the clarification step in conventional RO water treatment plant. Ultra filtrate water is effectively free of particles, colloidal particle and dissolved solids. Therefore, slotting of RO feed channels is reduced and the RO cleaning intensity can be notably minimized with this integration method. The operating pressure decreases with rate of removal of most pollutants and increases with system membrane flux. The integrated system (UF-RO combined process) observation shows that the dual-membrane process is an excellent option for the water treatment purifying process, with the efficiency of low water efficiency standards, superior water value, high recovery etc. The RO membrane effectively discards pollutants and maintains a sufficient sum of life saving elements, meeting norms for high quality potable water thus, the UF-RO integrated combined process is best suited for the design of direct drinking water system.

\section{ACKNOWLEDGEMENT}

The author would like to cknowledge the Chairman of St. Joseph's college of engineering, Chennai, India for his professional advice and comments.

\section{Conflicts of interest}

The authors declare no conflicts of interest.

\section{REFERENCES}

1. Majlinda Daci-Ajvaz.; Bashkim Thaç.; Nexhat Dac.; and Salih Gashi., Orient. J. Chem., 2016, 32, 2391-2400.

2. Selvi,S.R.; Baskaran,R.; Current science., 2015, 109(7), 1247-1254.

3. Selvi,S.R.; Baskaran,R.; International journal of engineering science and technology., 2015, 7(8), 267-278.

4. Selvi,S.R.; Baskaran,R.; International journal of chem tech research., 2014, 6(5), 2628 -2638.

5. Selvi,S.R.; Baskaran,R.; International Journal of chem Tech Research., 2015, 8(11), 211-220.
6. VinodKumar,S.;Baskaran,R.; IEEE., 2019, 1, 275-281.

7. VinodKumar,S.;Baskaran,R.;.Studia Rosenthaliana (Journal for the Study of Research)., 2020, XII(II), 66-71.

8. VinodKumar,S.;Baskaran,R.;.Journal of Xi'an University of Architecture \& Technology., 2020, XII(III), 5411-5417.

9. VinodKumar,S.;Baskaran,R.; Journal of Xidian University., 2020, 14(4), 696-701.

10. VinodKumar,S.;Baskaran,R.; International J. Advan. Scie. Tech., 2020, 29, 4450-4454. 